\title{
Recovery of gold(0) nanoparticles from aqueous solutions using effluents from a bioremediation process
}

\author{
Ana Assuncão ${ }^{1}$, Bernardete Vieira ${ }^{1}$, João P. Lourenço ${ }^{2,3}$ and Maria Clara Costa ${ }^{1,3 *}$ \\ (1) Centro de Ciências do Mar (CCMAR); Faculdade de Ciências e Tecnologia, \\ Universidade do Algarve, Campus de Gambelas, 8005-139 Faro, Portugal; \\ (2) Centro de Química Estrutural (CQE), Instituto Superior Técnico, Universidade de \\ Lisboa, Av. Rovisco Pais, 1096-001 Lisboa, Portugal \\ (3) Departamento de Química e Farmácia; Faculdade de Ciências e Tecnologia, \\ Universidade do Algarve, Campus de Gambelas, 8005-139 Faro, Portugal; \\ ${ }^{*}$ Corresponding author, e-mail: mcorada@ualg.pt, Fax: +351 289818419
}

\section{ABSTRACT}

The use of biological processes aiming the recovery of gold from low concentrated solutions coming from leaching of secondary sources is gaining increasing importance due to the scarcity of the primary resources and to the economic and environmental advantages usually presented by these methods. Thus, the addition, in batch and in continuous, of different solutions containing biogenic sulphide, generated by the activity of sulphate-reducing bacteria (SRB), to gold(III) solutions, was investigated for that purpose. In the batch experiments, AuS nanoparticles nanoparticles with sizes between 6 and $14 \mathrm{~nm}$ where obtained (corresponding to $100 \%$ of $\mathrm{Au}(\mathrm{III})$ removal from solution) if the biogenic sulphide was generated in a typical nutrient medium for $S R B$, while $A u(0)$ nanoparticles with sizes below $8 \mathrm{~nm}$, where attained (corresponding to $62 \%$ of $\mathrm{Au}$ (III) removal) if an effluent from a SRB bioremediation process to treat acid mine drainage (AMD) was used instead. These results stimulated the development of a continuous process of addition in which two sulphide-rich effluents, resulting from a SRB bioremediation process treating two types of AMD (from an uranium mine and from a polysulphide mine) were tested. In both cases $\mathrm{Au}(0)$ nanoparticles with sizes between 6 and $15 \mathrm{~nm}$ where mainly obtained, being the percentages of $\mathrm{Au}$ (III) removal from solution from $76 \%$ to $100 \%$. The processes described allow the simultaneously treatment of AMD and the obtainment of metallic gold nanoparticles, a product with high applicability (e.g. in medicine, optical devices and in catalysis) and economic value. The synthesis process described in this work can be considered a novelty, since it is the first time, to our knowledge, that the 
use of an effluent from a SRB bioremediation process is reported for gold(III) recovery as gold(0) nanoparticles.

Keywords: Gold, Nanoparticles, Bioremediation, Acid Mine Drainage, SulphateReducing Bacteria

\section{INTRODUCTION}

Gold, a precious metal with singular beauty due to its colour, has been historically a subject of great interest due to its characteristics, which include excellent electrical conductivity, low contact electrical resistance, outstanding corrosion resistance and low toxicity. These unique characteristics confer on it specific applications. ${ }^{1}$ Nowadays, gold is used for several purposes such as jewellery, high-tech industries, medical applications and electronic and electrical industries. ${ }^{2-4}$ More recently, the use of gold nanoparticles (NPs) was extended to recognition DNA, hereditary medicine in hyperthermia of tumour, optical coatings, scanning tunnelling microscopes as conductive tips, as well as in catalysis. ${ }^{5-7}$

Due to its limited availability in nature, gold recovery from both primary and secondary sources is becoming increasingly important. ${ }^{8}$ Therefore, its recovery from aqueous solutions namely, those resulting from leaching of gold-containing wastes, has been subject of wide investigation. Several processes are described in literature and some of them report gold recovery as $\mathrm{Au}(0) \mathrm{NPs},{ }^{9,10,6}$ which can be advantageous due to their wide range of applications resulting from specific properties arising from their nanoscale. According to Cai and co-workers ${ }^{5}$ the biosynthesis of metal NPs usually presents high selectivity and can operate at room temperature and pressure, without requiring reagents addition.

The physical and chemical conventional methods used in the synthesis of gold NPs are frequently toxic to the environment due to the use of toxic reagents, or due to the use of extreme temperature and pressure conditions, which increases the complexity and costs of the processes. Therefore, the interest in building "green" technologies for the synthesis of gold NPs has also increased, and consequently the interest and development of biological processes has attracted special attention. For the biosynthesis of gold NPs many biological systems have been proposed, such as, systems based on the use of fungi, ${ }^{11-13}$ algae, ${ }^{14,15,10}$ bacteria $^{9,16}$ and plants ${ }^{17-19}$. For example, Shewanella algae was able to reduce $\mathrm{Au}(\mathrm{III})$ ions with the assistance of hydrogen gas, forming extracellular gold NPs with a size between $10-20 \mathrm{~nm} .{ }^{14}$ The fungi Verticillium sp, ${ }^{20}$ Fusarium oxysporum ${ }^{21}$ and the actinomycete Thermomonospora 
$s p^{22}$ and Rhodococcus $s p^{23}$ were also used to synthesize NPs intra- or extracellularly. Recently, investigations on Rhodopseudomonas capsulata was conducted on the reduction of $\mathrm{Au}(\mathrm{III})$ ions forming gold nanoplates. ${ }^{9}$ The synthesis of gold NPs may occur inside or outside the cells, however, being preferable the extracellular synthesis, since it simplifies the downstream process, making it more efficient and consequently less expensive, aiming the applications of the obtained particles.

Sulphate-reducing bacteria (SRB) have been described as having bioremediation potential for metals removal during downstream processing from a range of industrial plants. ${ }^{24}$ Once under anaerobic conditions, SRB reduce sulphate to sulphide, which leads to the formation of metal sulphide precipitates. ${ }^{25}$ Nevertheless, SRB are used successfully in processes that involve the removal of metals and sulphate from Acid Mine Drainage (AMD) ${ }^{26}$ The metal sulphide precipitation has many advantages, including the production of lower sludge volumes and lower solubility products, comparing to hydroxide precipitation. Moreover, it is possible to recover the metals from the sulphide sludge ${ }^{24}$ Bhagat and colleagues ${ }^{27}$ demonstrated the use of sulphide generated by SRB for the removal of $\mathrm{Au}(\mathrm{III}), \mathrm{Cu}(\mathrm{II})$ and $\mathrm{Fe}$ (III) from aqueous solutions and the obtained precipitates were mostly metal sulphides, namely gold(I) sulphide.

The traditional processes for AMD remediation, based on the chemical neutralization and hydroxides precipitation, have some disadvantages, such as, high cost, low efficiency in sulphate's remediation and the formation of large sludge volumes, which requires a process for disposal. ${ }^{28}$ In alternative, bioremediation processes have been developed, particularly using SRB. ${ }^{29-31}$ The SRB in anaerobic conditions has the ability to oxidize simple organic compounds, using sulphate as an electron acceptor, reducing it to sulphide. ${ }^{32}$ The contact of the metal ions dissolved, for example, iron, copper and zinc, with the biological generated sulphide, causes the metals precipitation, as metal sulphides. ${ }^{33-35,29}$

Recently, Vitor and colleagues ${ }^{35}$ have used an effluent containing sulphide resulting from a SRB bioremediation process for AMD treatment, for the synthesis of several metal sulphides and respective $\mathrm{TiO}_{2}$ nanocomposites, in particular, $\mathrm{ZnS}$ and $\mathrm{ZnS} / \mathrm{TiO}_{2}$.

The present paper describes the recovery of $\mathrm{Au}(0) \mathrm{NPs}$ from gold(III) aqueous media by the addition of several solutions containing sulphide biologically generated by SRB, including effluents from the AMD bioremediation process reported by Vitor and colleagues $^{35}$. The use of such effluents allows the production of $\mathrm{Au}(0)$ NPs through an innovative, low-cost and environmentally safe synthesis process, thus contributing for 
the development of new and sustainable technologies that do not require the use of extreme conditions and/or expensive chemicals.

\section{EXPERIMENTAL}

\subsection{Batch experiments for gold recovery}

The batch experiments for gold recovery using filtrated supernatant from SRB growth in nutrient medium (Experiment $A 1$ ) and using bioreactor's effluent from a SRB bioremediation process for AMD treatment (Experiment A2) are represented in figure 1.

\subsubsection{Using the supernatant from the batch growth of $S B R$ in nutrient medium}

A SRB community enriched from the wetland of Urgeiriça mine (North of Portugal), grown and maintained in sub-cultures originally containing species mainly affiliated to Desulfovibrio desulfuricans ${ }^{36}$ was used as inoculum. This culture was grown and maintained in modified Postgate $\mathrm{B}$ medium ${ }^{32}$ with the following composition: 0.5g.L $\mathrm{L}^{-1} \quad \mathrm{~K}_{3} \mathrm{PO}_{4} \cdot \mathrm{H}_{2} \mathrm{O} ; 1 \mathrm{~g} \cdot \mathrm{L}^{-1} \quad \mathrm{NH}_{4} \mathrm{Cl} ; 1 \mathrm{~g} \cdot \mathrm{L}^{-1} \mathrm{CaSO}_{4} \cdot 2 \mathrm{H}_{2} \mathrm{O} ; 1 \mathrm{~g} \cdot \mathrm{L}^{-1}$ yeast extract; $2 \mathrm{~g} \cdot \mathrm{L}^{-1}$ $\mathrm{MgSO}_{4} .7 \mathrm{H}_{2} \mathrm{O} ; 0.01 \mathrm{~g} \cdot \mathrm{L}^{-1}$ resazurin; 0.5g. $\mathrm{L}^{-1} \quad \mathrm{Na}_{2} \mathrm{SO}_{3} ; 7.75 \mathrm{~g} \cdot \mathrm{L}^{-1} \mathrm{C}_{3} \mathrm{H}_{5} \mathrm{NaO}_{3}$ ) in $120 \mathrm{~mL}$ glass bottles, at room temperature $\left(21 \pm 1^{\circ} \mathrm{C}\right)$ in anaerobic conditions, achieved by purging the medium with nitrogen gas and $10 \mathrm{~mL}$ of sterile liquid paraffin, was added. Throughout the experiments, $\mathrm{pH}$, redox potential (Eh), sulphate and sulphide concentrations were determined weekly in order to monitor the bacterial growth.

After 28 days of growth, a $30 \mathrm{~mL}$ sample was collected, centrifuged at $4000 \mathrm{rpm}$ for $10 \mathrm{~min}$ and filtered on a $0.22 \mu \mathrm{m}$ filter (syringe filter, Puradisc FP 30 , Whatman) to avoid the presence of bacteria and obtain a solution resulting from the bacterial growth.

$25 \mathrm{~mL}$ of a gold(III) solution (Sigma-Aldrich, Gold atomic spectroscopy standard concentrate, $1.00 \mathrm{~g} / \mathrm{L} \mathrm{Au}$ standard solution) with gold concentration of $67 \mathrm{mg} / \mathrm{L}$ was added in $30 \mathrm{~mL}$ glass bottles. The bottles were then sealed with butyl rubber stoppers and aluminum seals. $5 \mathrm{~mL}$ of the filtrate solution from the bacterial growth was added to the gold(III) solution under stirring, drop-by-drop, using a syringe.

$\mathrm{pH}$, Eh, sulphate and sulphide concentrations were measured both in the filtrate and in the samples of the mixture collected after 1,3 and 7 days of contact. The concentration of gold(III) was also analyzed.

All assays were performed with four replicas and were carried out under sterile conditions. Figure 1-A1, represents a scheme of this batch experiment.

In order to understand the role played by sulphide in gold(III) removal, a similar assay was made using a chemical sulphide solution $\left(\mathrm{Na}_{2} \mathrm{SO}_{3}\right.$, Panreac) instead of the filtrate obtained after bacterial growth. The used sulphide solution had $200 \mathrm{mg} / \mathrm{L}$ of 
sulphide, a similar concentration to the one present in the filtrate resulting from SRB growth. That experiment was performed in duplicate under sterile conditions.

\subsubsection{Using a bioreactor's effluent from a SRB bioremediation process for $A M D$} treatment

In these experiments, the gold(III) solution with a gold concentration of 180 $\mathrm{mg} / \mathrm{L}$ was placed in $120 \mathrm{~mL}$ glass bottles. The bottles were capped with butyl rubber stoppers and a needle was placed in the rubber to relieve the pressure. The bioreactor's effluent (from BRI) was collected, filtered on a $0.22 \mu \mathrm{m}$ filter (syringe filter, Puradisc FP 30, Whatman) and added drop-by-drop with the syringe to the gold(III) solution under stirring, as shown in figure 1-A2.

In this assay, the volume of the added bioreactor's effluent was selected in order to have a molar ratio between sulphide and gold(III) of 1.5. The batch assays were carried out in duplicate, at room temperature, using sterilized material through autoclaving.

The filtrated bioreactor's effluent parameters, as $\mathrm{pH}$, Eh, sulphate and sulphide concentrations, were analyzed and the results are showed in table 1. After the addition of the bioreactor's effluent to the gold(III) solution, samples were collected at different times: after 1 hour and after 1, 3 and 7 contact days. In these samples the $\mathrm{pH}$, Eh, sulphate and sulphide concentrations and gold(III) concentration were also measured.

\subsection{Continuous experiments for gold recovery}

Effluents from a bioremediation process for AMD treatment were used to recover gold(III) from an aqueous solution, in a continuous system. The effluent from Bioreactor I (BRI) was obtained in bioremediation's treatment of AMD from $S$. Domingos' Mine (Experiment B1), while the effluent from Bioreactor II (BRII) was obtained in the treatment of AMD from Quinta do Bispo's Mine (Experiment B2). Figure 2 shows a scheme of the continuous experiments.

In the continuous system, aiming at gold recovery, the gold(III) solution was coupled downstream to the bioremediation process. In this system described in figure 2, two bioreactor's effluents were tested, one from the treatment of the AMD from $S$. Domingos' mine (BRI) (figure 2-B1) and the other from the treatment of an AMD coming from the uranium mine of Quinta do Bispo, located in North Portugal (BRII) (figure 2-B2). Both AMD were neutralized with calcite tailing, before entering the bioreactor to ensure a suitable $\mathrm{pH}$ for the growth and activity of SRB in the bioreactor, as shown in the first step of figure 2 . 
Previous experience as shown that a combined process consisting of an anaerobic sulphate- reducing bioreactor, following neutralization with calcite tailing, produces water complying with legal irrigation requirements from synthetic AMD. ${ }^{35}$

In all the experiments, the bioreactor's effluent was added to the gold(III) solution, drop-by-drop, using a syringe under stirring.

\subsubsection{Bioreactor's effluent characterization}

The bioreactor's effluents produced in this bioremediation process had sulphide generated by the SRB present in the bioreactor. This sulphide is an environmental hazard, ${ }^{37,38}$ thus a system was designed to use it, aiming gold recovery from an aqueous solution, under controlled conditions. The bioreactor is an Upflow Anaerobic Packed-Bed Reactor (UAPB) inoculated with a SRB community and the AMD bioremediation processes contain an additional upstream neutralization step, as described by Victor and colleagues. Ethanol was used as carbon source to promote SRB growth and activity and phosphorous and nitrogen were also added regularly.

The BRI was treated AMD from the polysulphide mine of $S$. Domingos (containing several metals such as $\mathrm{Fe}, \mathrm{Cu}$ and $\mathrm{Zn}$ ), while BRII was treating AMD from the uranium mine of Quinta do Bispo (containing metals such as Fe, $\mathrm{Al}, \mathrm{Mn}$ and $U$ ). The effluents of both bioreactors (BRI and BRII) were characterized in terms of $\mathrm{pH}$, Eh and concentrations of sulphate and sulphide and the results are displayed in table 2.

The system used for gold recovery consisted in a $1 \mathrm{~L}$ reaction vessel containing gold(III) solution under stirring (Velp Scientifica ARE magnetic stirrer) in which the bioreactor's effluent was collected drop-by-drop, as demonstrated in figure 2.

In the experiment with the effluent from BRI, the initial $A u(I I I)$ concentration in metal solution was $100 \mathrm{mg} / \mathrm{L}$, while in the experiment with effluent from BRII, the $\mathrm{Au}$ (III) concentration was $200 \mathrm{mg} / \mathrm{L}$ and in both cases the gold(III) solutions were deaerated in an ultrasound bath (J.P. Selecta Ultrasons-H) for $15 \mathrm{~min}$.

The possible contamination of the gold precipitate with bacteria and/or metals precipitates from the bioreactor was avoided by using a filter system placed immediately before the reaction vessel. That filter was composed by a coarse glass wool pre-filter in a glass column (14 cm long, $2 \mathrm{~cm}$ diameter), followed by a $0.2 \mu \mathrm{m}$ syringe filter (Whatman Puradisc 25 AS), as described by Vitor and colleagues ${ }^{35}$. The volume of the bioreactor's effluent was added until a molar ratio of 1.5 between sulphide (from the effluent) and gold(III) was achieved. After the effluent's addition the parameters of the mixture were measured $(\mathrm{pH}$, redox potential, sulphate and sulphide concentrations and gold concentration) and the precipitate was characterized. 


\subsection{Analytical methods}

In order to monitor the growth of the SRB community, samples from the batch cultures were periodically collected using a sterile syringe and the optical density at $600 \mathrm{~nm}\left(\mathrm{OD}_{600}\right)$ was measured in each sample. After centrifugation at $4000 \mathrm{rpm}$ for 5 min, redox potential and $\mathrm{pH}$ were determined using a $\mathrm{pH} / \mathrm{E}$ Meter (GLP 21, Crison) and the sulphate concentration was quantified by UV-visible spectrophotometry (HachLange DR2800 spectrometer) using the method of SulfaVer®4.

As mentioned above, in the batch experiments, samples were periodically collected, while in the continuous experiments the samples were collected at the end of the bioreactor's effluent addition.

In the mixtures containing the gold(III) solution and the sulphide solution, the sulphide concentration was measured immediately after sampling, using an UV-Visible spectrophotometer (DR 2800, Hach-Lange) by the Methylene Blue Method (665 nm, Hach-Lange). After centrifugation at $4000 \mathrm{rpm}$ for $5 \mathrm{~min}$, redox potential, $\mathrm{pH}$ and sulphate concentration were also measured using the same methodology and equipment described above. The gold(III) concentration was analysed using the thiamine-phloxine method described by Fujita and colleagues ${ }^{39}$. In an assay tube with $1 \mathrm{~mL}$ of the test solution, $0.5 \mathrm{~mL}$ of $0.5 \%(\mathrm{w} / \mathrm{v})$ methylcellulose, $1 \mathrm{~mL}$ of $10 \mathrm{mM}$ thiamine, $2 \mathrm{~mL}$ of EDTA-citrate buffer (0.05 M EDTA, 0.1Mcitric acid pH 4.6), $1 \mathrm{~mL}$ of 1 $\mathrm{mM}$ phloxine B (Sigma-Aldrich Chemical Company) and $4.5 \mathrm{~mL}$ of distilled water were added. The tubes were incubated in a water bath $\left(20 \mathrm{~min}, 40^{\circ} \mathrm{C}\right)$ and the absorbance was measured at $570 \mathrm{~nm}$ after cooling. The blank was prepared the same way as the samples by replacing the gold sample by distilled water. ${ }^{40}$

\subsection{Precipitates characterization}

The precipitates obtained in the different experiments were characterized. In order to recover the precipitates, samples of the mixture were collected, centrifuged at $4000 \mathrm{rpm}$ for $10 \mathrm{~min}$ and the pellets were washed 3 times with ethanol $70 \%$ and the precipitates were then dried in vacuum (Binder, VDL) at $37^{\circ} \mathrm{C} \pm 1^{\circ} \mathrm{C}$.

The obtained precipitates were analysed by X-Ray Diffraction (XRD) using a PANalytical X'Pert Pro powder diffractometer, operating at $45 \mathrm{kV}$ and $35 \mathrm{~mA}$, with $\mathrm{Cu}$ $\mathrm{K} \alpha$ radiation filtered by $\mathrm{Ni}$. The XRD patterns were recorded using an X'Celerator

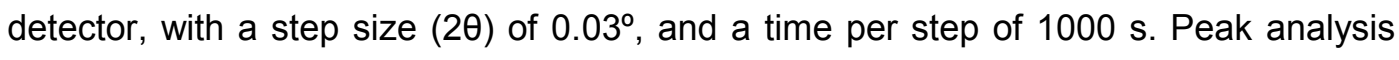
and crystalline phase identification were conducted using the High-Score Plus software, with the ICDD PDF-2 database.

Transmission Electron Microscopy (TEM) (Hitachi, H8100 model, with a LaB6 filament) coupled to Energy Dispersive X-ray Spectroscopy (EDS or EDX) 
(ThermoNoran) were used for the determination of the particles size, morphology and elemental composition.

\section{RESULTS AND DISCUSSION}

Metals are usually toxic for microorganisms, such as SRB, since essential ions can be substituted on cellular sites causing functional groups blockage of important molecules such as enzymes. ${ }^{41}$ Therefore, in the present work solutions resulting from SRB growth in several conditions were added to $\mathrm{Au}$ (III) solutions, instead of the direct addition of gold(III) to the nutrient medium during bacterial growth. The advantage of the present methodology is the fact that it does not require the use of metal-resistant bacteria. A solution resulting from SRB growth and two effluents from a SRB bioremediation process described by Victor and colleagues ${ }^{35}$ for AMD treatment were used for that purpose. As described in figure 1 the experiments were carried out in batch (Experiments $\mathrm{A} 1$ and $\mathrm{A} 2$ ) and in a continuous system (Experiments $\mathrm{B} 1$ and $\mathrm{B} 2$ ).

\subsection{Batch experiments for gold recovery}

The batch experiments for gold recovery were performed using the filtrated solution resulting from SRB growth in batch, in nutrient medium (Experiment A1) and the bioreactor's effluent collected from BRI (Experiments A2).

The filtrated solution used in experiment A1 was obtained after SRB growth for 28 days. After that time around $55 \%$ of sulphate was consumed, producing $247 \mathrm{mg} / \mathrm{L}$ of sulphide. The optical density $(600 \mathrm{~nm})$ of the solution reached 0.6 , due to high bacterial growth. The molar ratio between gold(III) and sulphide in the experiment was $1: 1.5$.

The $\mathrm{A} 1$ experiment showed that in one hour all $\mathrm{Au}(\mathrm{III})$ was removed from the solution and a dark precipitate was formed. This result was followed by the removal of $93 \%$ of sulphide, which may indicate that the sulphide present in the filtrated solution might be responsible for the $\mathrm{Au}$ (III) removal. In order to prove this hypothesis, an assay using a "chemical" sulphide solution with a sulphide concentration of $200 \mathrm{mg} / \mathrm{L}$ was performed in the same batch conditions. The results are shown in figure $3 \mathrm{~A}$ and demonstrate that sulphide seems to be responsible for gold precipitation.

In experiment A2, a brown precipitate was formed. The removal of gold(III) did not exceed $62 \%$, as shown in figure $3 \mathrm{~B}$, while, in assay $\mathrm{A} 1$ the removal was complete (100\%) and almost immediate. The different percentage of $\mathrm{Au}(\mathrm{III})$ removal from the solution and the different colour of the precipitate obtained can indicate that different gold precipitates were formed. Eventually, these results could be associated to the 
different molar ratio between sulphide and gold(III) used in each experiment, or to the different composition of the biologically generated sulphide solution, considering that one resulted from SRB growth in nutrient medium (A1) and the other from the treatment of AMD (A2). In experiment A1 the ratio between sulphide and gold was 15 , thus there were more sulphide species available to interact with gold(III), when compared with experiment $A 2$, in which the ratio was 10 times lower (1.5).

Furthermore, a longer contact time between the metal ion and sulphide does not influence $A u(I I I)$ removal, since in experiment $A 1, A u(I I I)$ removal within the first hour remained constant independently of the presence of sulphide in the solution, as shown in figure $3 \mathrm{~B}$. Therefore, the interaction between the sulphide and gold(III) ions occurs within the first hour. The decrease of sulphide during the rest of the assay can be related to $\mathrm{H}_{2} \mathrm{~S}$ volatility, since whenever a sample was collected the sulphide concentration in the solution decreased.

In both experiments the $\mathrm{pH}$ also decreased after the addition of the biogenic sulphide to the gold(III) solution. However, in experiment $\mathrm{A} 1$ a higher $\mathrm{pH}$ decrease was achieved (8.47 to 2.50), while, in experiment $\mathrm{A} 2$ the $\mathrm{pH}$ decreased from 8.09 to 5.58. The initial $\mathrm{pH}$ of the gold(III) solution used in both experiments varied between 1.76 and 1.95, which contributes for the $\mathrm{pH}$ decrease in the mixture. The $\mathrm{pH}$ decrease can also be related with the dissociation of $\mathrm{H}_{2} \mathrm{~S}$, as the sulphide reacts with gold(III) ions. ${ }^{27}$

\subsubsection{Precipitates characterization}

The precipitates from experiments $A 1$ and $A 2$ were washed and dried for subsequent characterization by XRD and TEM-EDS, in order to determine the crystallography of the precipitate and the particles morphology and size, respectively.

The XRD diffractograms of the obtained gold precipitates are shown in figure 4.

The XRD analysis corresponding to $(A)$ and $(B)$ diffractograms were not totally conclusive. Some broad peaks (identified as $(\mathrm{x})$ ) may correspond to $\mathrm{Au}_{2} \mathrm{~S}$ (ICDD PDF2 \# 01-085-1997). These non-conclusive results of XRD can be associated to the very small size of the particles, which is consistent with the subsequent results of Transmission Electron Microscopy (TEM).

The XRD diffractogram shown in figure $4 \mathrm{C}$, is more conclusive, since the peaks (identified as $(*)$ in the diffractogram) indicate the presence of metallic gold particles, which could be indexed on the basis of the cubic gold structure (ICDD PDF2 \# 01-0714615). The first peak, not identified in the diffractofram is a typical sulphur peak, which indicates that some elemental sulphur is also present in the sample.

A TEM-EDS analysis of the same precipitates was also performed. The TEM characterization of the precipitate obtained in experiment $A 1$, figure 5-A1 $A$ and $B$, 
confirms that the particles are NPs with very small sizes, between 6-14 nm, which may explain the results of XRD analysis. In addition, those NPs are present in agglomerates. In addition, those NPs are present in agglomerates. In fact, the values of zeta potential obtained for $A u(0)$ NPs resulting from experiment A2 decrease from $17.2 \mathrm{mV}$ at $\mathrm{pH} 2.00$ to values near $-24 \mathrm{mV}$ at $\mathrm{pH} 4$ or higher, indicating that the $\mathrm{Au}(0)$ NPs are susceptible to form clusters, throughout the tested range of $\mathrm{pH}$ values. This phenomenon is due to Van der Walls inter-particles attractions occurring in NPs with zeta potential range between $-30 \mathrm{mV}$ and $+30 \mathrm{mV}{ }^{42}$

The Energy Dispersive X-ray (EDS) spectrum only shows peaks of the elements $\mathrm{Au}$ and $\mathrm{S}$, figure $5-\mathrm{A} 1 \mathrm{C}$, which are consistent with the formation of gold sulphide NPs. In the EDS, the element percentage of sulphur and gold was $69 \%$ and $31 \%$, respectively. The higher percentage of the element $\mathrm{S}$ in comparison to Au can be justified by the excess of sulphur in the precipitate, thus not all sulphur react with $\mathrm{Au}$ to produce $\mathrm{Au}_{2} \mathrm{~S}$, but some elemental sulphur may also had been formed.

TEM-EDS results of the obtained precipitates, in experiment $A 2$, are shown in figure 5-A2. The precipitates were mainly composed by spherical gold NPs agglomerated with a size smaller than $8 \mathrm{~nm}$ (figure 5-A2 A and B). The EDS spectrum, figure $5 \mathrm{C}$, shows the presence of $\mathrm{Au}$. The $\mathrm{Cu}$ element also identified in both EDS spectrum belongs to the sample grid.

In order to understand if it would be possible to obtain similar results in a continuous system, using effluents produced in an AMD bioremediation process, the replace of the batch system for the continuous system was carried out. For that purpose, effluents from two different AMD bioremediation processes were tested, downstream to the bioreactor.

\subsection{Continuous system for gold recovery}

The experiments developed in a continuous system for $\mathrm{Au}(\mathrm{III})$ recovery were performed using bioreactor's effluents from two AMD bioremediation processes. The main difference between these two effluents was the treated $A M D$ and the initial concentration of the gold(III) in the solution. BRI treats AMD from S. Domingos' mine while Bioreactor II treats AMD from the uranium Quinta do Bispo's mine.

Although, two different gold(III) concentrations, were used, the molar ratio between sulphide (from the effluent) and gold(III) was maintained at 1.5 , since in the batch assays it was demonstrated that this is the most suitable ratio to obtain gold(III) removal percentages up to $60 \%$ as metallic gold NPs. In the continuous assays, the time required to achieve this ratio depends on the AMD flowrate. The flowrate in these 
bioreactors ranged from 2.5 to $5.0 \mathrm{~mL} / \mathrm{h}$ and the experiments lasted no more than 25 hours.

Sequential pictures of the continuous system aiming gold recovery, using bioreactor's effluent from AMD bioremediation process, are shown in figure 6 .

The $\mathrm{pH}$ profile was similar to the one obtained in batch assays. Thus, in both continuous experiments, $\mathrm{B} 1$ and $\mathrm{B} 2$, the $\mathrm{pH}$ decreased from values 6.44 and 6.83 to 2.36 and 2.52 values, respectively. As mentioned above, this $\mathrm{pH}$ decrease is associated to the addition of the gold(III) solution with a pH lower than 2 .

When the bioreactor's effluent started to be added, drop-by-drop, to the gold(III) solution (figure $6 \mathrm{I}$ ), the formation of a brown and bright precipitate was observed (figure $6 \mathrm{II}$ and III). The sulphide from both effluents is probably able to reduce $\mathrm{Au}(\mathrm{III})$ into insoluble $\mathrm{Au}(0)$ (figure $6 \mathrm{II}$ and III), which is consistent with the result obtained in the batch assays when the bioreactor's effluent was added to Au(III) solution.

Figure 7 contains the percentages of gold(III) and sulphide removal from the solution obtained in both continuous assays.

In experiment B1, gold(III) and sulphide removal achieved values of $76 \%$ and $95 \%$, respectively, while in experiment B2 the removal of gold(III) and sulphide reached $100 \%$ and $73 \%$, respectively.

The results showed that gold removal percentages higher than $76 \%$ can be achieved regardless of the effluent used. However, the percentage of gold recovery is probably dependent on the effluent composition.

\subsubsection{Precipitate's characterization}

The precipitates obtained in the continuous experiments (B1 and B2) were washed, dried and characterized by XRD and TEM-EDS.

Despite the different percentages of gold removal, $76 \%$ and $100 \%$, using the bioreactor's effluents, from BRI and BRII, respectively, the characterization of the precipitates has shown to be very similar.

The XRD analysis of the precipitates obtained in experiments B1 and B2 are presented in figure 8.

A similar XRD pattern was obtained for both precipitates and the results are consistent with $\mathrm{Au}(0)$ particles, which could be indexed on the basis of the cubic gold structure (ICDD PDF2 \# 01-071-4615), as shown in the batch experiments with this bioreactor's effluent (Experiment A2), but with more intense and sharp peaks.

XRD pattern revealed intense peaks of Bragg's reflections corresponding to (1, $1,1),(2,0,0),(2,2,0),(3,1,1)$ and $(2,2,2)$ at $2 \theta$ values of $38.2^{\circ}, 44.5^{\circ}, 64.7^{\circ}, 77.7^{\circ}$ and $81.2^{\circ}$, respectively. No spurious diffractions, due to crystallographic impurities, 
were found. The XRD patterns of the samples compared to the standard patterns of gold(0) (represented by '*') with typical peaks for zero-valent gold, confirms that the precipitates are effectively $\mathrm{Au}(0)$.

TEM results of the precipitates obtained in experiments B1 and B2 revealed that there are mainly two different shapes, morphology and sizes, as shown in figure 9 . In the experiment B1, the particles with hexagonal morphology are bigger and present a size range of $30-80 \mathrm{~nm}$, while the particles with spherical morphology are smaller, ranging 6-10 nm (figure $9 \mathrm{~A}$ and $\mathrm{B}$ - Exp B1). The particles are mostly found in agglomerates and the EDS analysis identified only peaks corresponding to Au (figure 9 $C-\operatorname{Exp} B 1$ ), thus corroborating the XRD results.

$A$ representative TEM image of the obtained precipitates in experiment $B 2$ is represented in figure 9 A and B - Exp B2 and reveals a spherical shape of the NPs with a size range of $8-15 \mathrm{~nm}$. The EDS analysis, figure $9 \mathrm{C}-\operatorname{Exp} B 2$, confirms the result obtained by $X R D$, once gold was the only element identified in the precipitate. The identification of $\mathrm{Cu}$ is due to the composition of the sample grid.

Table 3 shows a summary of the results obtained in both systems batch and continuous for each experiment.

The results obtained in experiment A1 suggest that the sulphide produced during bacterial growth, in nutrient medium, was able to remove gold(III) from aqueous solution, as gold(I) sulphide NPs, meaning that gold(III) was previously reduced to gold(I), which was combined to the biologically generated sulphide present in solution. Therefore, the production of gold $(I)$ sulphide occurred when the conditions to reduce gold(III) to gold(I) were created and whenever biogenic sulphide was available.

A similar study was already performed in which a bioreactor was used operating on a fill-and-draw basis, using Postgate medium as feed to favour the SRB growth. The sulphide produced by SRB community was used to metals (Fe(III), $\mathrm{Cu}(\mathrm{II})$ and $\mathrm{Au}(\mathrm{III})$ ) precipitation by sparging the metals solution with biogenic sulphide gas or by mixing it with sulphide-rich supernatant from a sulphate reducing bioreactor feed with nutrient medium, without the need of biomass. The obtained precipitates are mainly metal sulphides and also contained unidentified complexes which could include nitrates, chlorides and carbonates. ${ }^{27}$ For the assays with gold(III), a black gold(I) sulphide precipitate was formed when biogenic sulphide was bubbled through an $\mathrm{Au}(\mathrm{III})$ solution according to the eq. (1), described by Vogel ${ }^{43}$ :

$$
2\left[\mathrm{AuCl}_{4}\right]^{-}+3 \mathrm{H}_{2} \mathrm{~S} \longrightarrow \mathrm{Au}_{2} \mathrm{~S} \downarrow+2 \mathrm{~S} \downarrow+6 \mathrm{H}^{+}+8 \mathrm{Cl}^{-} \quad \text { Eq. (1) }
$$


As suggested by Bhagat and colleagues ${ }^{27}$, at room temperatures, elemental gold is dispersed with $\mathrm{Au}_{2} \mathrm{~S}$.

It is expected that the same reaction is involved in the formation of $\mathrm{Au}_{2} \mathrm{~S}$ in our batch study, when the filtrated supernatant from SRB growth in nutrient medium (experiment A1) was used. Once this precipitate is heated to $200^{\circ} \mathrm{C}$ it decomposes to elemental gold. ${ }^{44}$ However, using the bioreactor's effluent (experiments A2, B1 and B2) elemental gold was obtained directly, without requiring the use of these high temperatures.

In our experiments, where bioreactor's effluents from AMD treatment were used, $\mathrm{Au}(0) \mathrm{NPs}$ were obtained instead of $\mathrm{Au}_{2} \mathrm{~S}$. We can speculate that the effluents contain compounds able to reduce $\mathrm{Au}(\mathrm{III})$ to $\mathrm{Au}(0)$ that were not present in the solution resulting from SRB growth in nutrient medium. No $A u(I I I)$ removal was observed when AMD was added to the $A u(I I I)$ solution, which may indicate that the reducing compounds resulted from bacterial activity. Indeed, biological reduction of gold(III) to gold $(0)$ has been reported but only in the presence of biomass. Cells of Magnetospirillum gryphiswaldense MSR-1 and Saccharomyces cerevisiae showed to be able to reduce gold(III) ions to a zero-valent metal and accumulate them on the cell surface through biosorption. ${ }^{5,45}$ Lin and colleagues ${ }^{45}$ suggested that the biosorption mechanism of $A u(I I I)$ involves an apparent redox reaction in which the ionic metal is reduced to the metallic form, as we suppose to occur in our case, but without the need of biomass. In the reported biosorption process, the hydroxyl and carboxylate ion groups of biomass played an important role in the $\mathrm{Au}(\mathrm{III})$ binding and consequent reduction to $\mathrm{Au}(0)$, mainly by the free aldehyde group of the reducing sugars. ${ }^{45}$

Actually, the reduction of $\mathrm{Au}(\mathrm{III})$ to $\mathrm{Au}(\mathrm{I})$ was already reported as an intermediated step before the formation of $A u(0)$ in experiments using different biomass, such as alfalfa, ${ }^{46}$ dealginated brown alga ${ }^{47}$ and Chlorella, a single-cell green algae $^{48}$. These authors have proposed a fast reduction of $A u(I I I)$ to $A u(I)$, while reduction to $A u(0)$ is reported as slow. ${ }^{10}$ In our experiments ( $A$ and $B$ ), the reduction of $\mathrm{Au}(\mathrm{III})$ to $\mathrm{Au}(\mathrm{I})$ occurs without biomass as support, and can be performed by chemical compounds from the nutrient medium and/or can be associated to the bacterial activity.

Some authors suggested that $\mathrm{NADH}^{-}$and $\mathrm{NADH}$-dependent enzymes are important factors in the biosynthesis of metal NPs. ${ }^{21,49,12,50}$ The potential of Rhodopseudomonas capsulata, one of the most ecological and environmentally important bacteria, commonly existing in natural environment, for $\mathrm{Au}(\mathrm{III})$ reduction was already studied. It was demonstrated that this bacteria, able to grow anaerobically, can successfully produce gold NPs of different sizes and shapes. The authors suggested that $R$. capsulata secrete cofactor $\mathrm{NADH}$ - and NADH dependent enzymes can be 
responsible for the $\mathrm{Au}(\mathrm{III})$ bioreduction to $\mathrm{Au}(0)$ with the formation of NPs. Although the $\mathrm{Au}(\mathrm{III})$ bioreduction mechanism played by $R$. capsulate is not well known, it was suggested that gold(III) reduction is initiated by electron transfer from the NADH by $\mathrm{NADH}$-dependent reductase, as electron carrier and then the gold ions are reduced to $\mathrm{Au}(0) .{ }^{9}$ Another possible explanation are the proteins, since they are the primary biomolecules involved in providing the function of $\mathrm{Au}$ (III) reduction and in the function of the size and shape controls. ${ }^{51}$

These hypothesises might explain the achievement of $A u(0)$ when the bioreactor's effluents were used and the achieved of $\mathrm{Au}_{2} \mathrm{~S}$ when the supernatant from the SRB growth on a nutrient medium was utilised. This can be related to the bacterial community present in experiment $\mathrm{A} 1$ and in experiments $\mathrm{A} 2, \mathrm{~B} 1$ and $\mathrm{B} 2$. The bacterial community in the bioreactor was probably richer in bacteria that secrete cofactor $\mathrm{NADH}$ - and NADH dependent enzymes, like $R$. capsulate, enabling the reduction of $\mathrm{Au}(\mathrm{III})$ to $\mathrm{Au}(0) \mathrm{NPs}$. Despite all the bacterial community used in the experiments have been enriched to benefit the sulphate-reducing bacterial growth, each one was subjected to different conditions, which can select a different composition of the SRB communities. The SRB community used to obtain the filtrated solution from bacterial growth was grown in culture medium, while the bioreactor's effluents were obtained from a SRB community previously acclimatized in the bioreactors with culture medium and then subjected to different AMD. This fact certainly changed the initial bacterial community, justifying the eventual production of different compounds during the bacterial growth and that may be involved in gold(III) bioreduction mechanism.

The results obtained in the present work suggest that it is possible to reduce $\mathrm{Au}(\mathrm{III})$ to $\mathrm{Au}(0) \mathrm{NPs}$ using bioreactor's effluents, rich in biogenic sulphide, from AMD bioremediation processes based on the activity of SRB. These results were obtained without the presence of biomass as reported in previous studies. The described process presents some economic advantages, due to the use of a bioreactor's effluent, able to replace chemical processes that use reagents, as $\mathrm{NaBH}_{4}$, citrate and ascorbate $^{6}$ for the removal/recovery of a valuable material such as $\mathrm{Au}(0)$. Furthermore, it takes advantage from the use of $\mathrm{H}_{2} \mathrm{~S}$, a toxic sub-product of the AMD bioremediation process, thus with additional environmental benefits.

\section{CONCLUSION}

The present work demonstrates, for the first time to our knowledge, the ability of effluents from a SRB bioremediation process for AMD treatment, containing biogenic 
sulphide, to efficiently remove gold(III) from solution, allowing its recovery as $\mathrm{Au}(0)$ NPs.

The reduction of gold(III) to metallic gold seems to be, not only dependent on the sulphide ions available in the solution, but may also be dependent on the presence of other compounds produced by the bacterial community in the bioreactor. It can also be concluded that the $A u(0)$ particles recovered in these processes are mostly NPs with very small sizes between 6 to $15 \mathrm{~nm}$ with a cubic crystalline structure, which confers them unique properties useful for specific applications.

The process described in this paper is an attractive alternative from both environmental and economic points of view to the traditional chemical methods usually utilized for gold recovery: it allows the valorization of an effluent and is performed at room temperature and pressure, thus avoiding the use of extreme conditions and expensive chemicals. Moreover, the possibility to recover gold as metallic NPs is very important taking into account their high market prices and diverse uses. The recent increase of gold share value may be justified by the significant value usually attributed to this metal during international political and economic crises and by its limited availability. Thus, we hope the process described in this work could be a promising contribution aiming to facilitate the recovery of gold as NPs, namely from secondary sources.

\section{ACKNOWLEDGEMENTS}

The authors wish to thank Fundação para a Ciência e a Tecnologia (FCT) for funding this research through the PhD grant SFRH/BD/77093/2011 and through the Projects UID/Multi/04326/2013, PTDC/AAG-TEC/2721/2012 and UID/QUI/00100/2013.

\section{REFERENCES}

1 S. Syed, Hydrometallurgy, 2012, 115-116, 30-51.

2 A. Ramesh, H. Hasegawa, W. Sugimoto, T. Maki, K. Ueda, Bioresour. Technol., 2008, 99, 3801-3809.

3 M. Spitzer, B. Rodnei, Hydrometallurgy, 2004, 74, 233-242.

4 H. Baba, Conserv. Recycling, 1987, 10, 247-252.

5 F. Cai, J. Li, J. Sun, Y. Ji, Chem. Eng. J., 2011, 175, 70-75. 
6 A.R. Binupriya, M. Sathishkumar, K. Vijayaraghavan, S.-I. Yun, J. Hazard. Mater., 2010, 177, 539-545.

7 S.S. Shankar, A. Rai, A. Ahmad, M. Sastry, Chem. Mater., 2005, 17, 566-572.

8 Y. Konishi, T. Tsukiyama, K. Ohno, N. Saitoh, T. Nomura, S. Nagamine, Hydrometallurgy, 2006, 81, 24-29.

9 S.Y. He, Z.R. Guo, Y. Zhang, S. Zhang, J. Wang, N.Gu, Mater. Lett., 2007, 61, 39843987.

10 Y.N. Mata, E. Torres, M.L. Blázquez, A. Ballester, F.González, J.A. Muñoz, J. Hazard. Mater., 2009, 166, 612-618.

11 K.C. Bhainsa, S.F.D. Souza, Colloids and Surfaces B, 2006, 47, 160-164.

12 S. Senapati, A. Ahmad, M.I. Khan, M. Sastry, R. Kumar, Small, 2005, 1, 517-520.

13 A. Ahmad, P. Mukherjee, S. Senapati, D. Mandal, M.I. Khan, R. Kumar, M. Sastry, Colloids Surface B, 2003, 28, 313-318.

14 Y. Konish, T. Normura, T. Tsukiyama, N. Saitoh, Trans. Mater. Res. Soc. Jpn., 2004, 29, 2341-2343.

15 G. Singaravelu, J.S. Arockiamary, V.G. Kumar, K. Govindaraju, Colloids Surface B, 2007, 57, 97-101.

16 R. Shahverdi, S. Minaeian, H.R. Shahverdi, H. Jamalifar, A. Nohi, Process Biochem., 2007, 42, 919-923.

17 M. Sathishkumar, K. Sneha, I.S. Kwak, J. Mao, S.J. Tripathy, Y.-S. Yun, J. Hazard. Mater., 2009, 171, 400-404.

18 M. Sathishkumar, K. Sneha, S.W. Won, C.-W. Cho, S. Kim, Y.-S. Yun, Colloids Surface $B, 2009,73,332-338$.

19 S.S. Shankar, A. Ahmad, M. Sastry, Biotechnol. Prog., 2003, 19, 1627-1631.

20 P. Mukherjee, A. Ahmad, M. Mandal, S. Senapati, S.R. Sainkar, M.I. Khan, R. Ramani, R. Parischa, P.V. Ajayakumar, M. Alam, M. Sastry, R. Kumar, Angew Chem. Int. Ed., 2001, 40, 3585-3588.

21 P. Mukherjee, S. Senapati, A. Ahmad, M.I. Khan, M. Sastry, Chem. Biochem., 2002, 3, 461-463.

22 A. Ahmad, S. Senapati, M.I. Khan, R. Kumar, M. Sastry, Langmuir, 2003, 19, 35503553.

23 A. Ahmad, S. Senapati, M.I. Khan, R. Kumar, R. Ramani, V. Srinivas, M. Sastry, Nanotechnology, 2003, 14, 824-828.

24 O.J. Hao, in IWA Publishing, P.N.L. Lens, L.H. Pol (Eds.), London, 2000, 393-414.

25 I.S. Chang, P.K. Shin, B.H. Kim, Water Res., 2000, 34, 1269-1277.

26 A.H. Kaksonen, M.-L. Riekkola-Vanhanen, J.A. Puhakka, Water Res., 2003, 37, 255-266. 
27 M. Bhagat, J.E. Burgess, A.P.M. Antunes, C.G. Whiteley, J.R. Duncan, Miner. Eng., 2004, 17, 925-932.

28 J. Chatterjee,, S. Dasgupta, J. Photoch. Photobio. C, 2005, 6, 186-205.

29 M.C. Costa, J.C. Duarte, Water Air Soil. Poll., 2005, 165, 325-345.

30 L. Diels, N. van der Lelie, L. Bastiaens, Rev. Environ. Sci. Biotechnol., 2002, 1, 7582.

31 U.S. Patent document $n^{\circ}$ 6,852,305 B2, 2/2005, Buisman and Dijkman.

32 JR Postgate (eds) Cambridge University Press, 1984, Cambridge.

33 S. Bractova, S. Groudev, P. Georgiev, in Annual of the University of Mining and Geology St Ivan Ritski, Part II, Mining and Mineral Processing, 2002, 123-127.

34 G. Cabrera, R. Pérez, J.M. Gómez, A. Ábalos, D. Cantero, J. Hazard. Mater., 2006, A135, 40-46.

35 G. Vitor, T.C. Palma, B. Vieira, J.P. Lourenço, R.J. Barros, M.C. Costa, Miner. Eng., $2015,75,85-93$.

36 M. Martins, M.L. Faleiro, S. Chaves, R. Tenreiro, M.C. Costa, Sci. Total Environ., 2010, 408, 2621-2628.

37 D. Mandal, M.E. Bolander, D. Mukhopadhyay, G. Sarkar, P. Mukherjee, Appl. Microbiol. Biot., 2006, 69, 485-492.

38 M. Labrenz, J.F. Banfield, Microb. Ecol., 2004, 47, 205-217.

39 Y. Fujita, I. Mori, T. Matsuo, Anal. Sci., 1999, 15, 1009-1012.

40 K. Deplanche, L.E. Macaskie, Biotechnol. Bioeng., 2008, 99, 1056-1064.

41 M. Martins, M.L. Faleiro, R.J. Barros, A.R. Veríssimo, M.C. Costa, Biodegradation, 2009, 20, 559-567.

42 N. Mandzy, E. Grulke, T. Druffel, Powder Technol., 2005, 160, 121-126.

43 J. Vogel, in Qualitative Inorganic Analysis, Longman Publishing Ltd, London, UK, 1996.

44 Puddephatt R.J., in Inorganic and General Chemistry-Monograph 16, Ed by R.J.H. Clark, Elsevier, Amsterdam, Oxford, New York, 1978, 274.

45 Z.Y. Lin, J.M. Wu, R. Xue, Y. Yang, Spectrochim. Acta A, 2005, 61, 761-765.

46 G. Gamez, K. Dokken, I. Herrera, J.G Parsons, K.J. Tiemann, J.L. GardeaTorresdey, in Proceedings of the 2000 Conference on Hazardous Waste Research, Denver, Colorado, 2000, 46-53.

47 M.E. Romero-González, C.J. Williams, P.H.E. Gardiner, S.J. Gurman, S. Habesh, Environ. Sci. Technol., 2003, 37, 4163-4169.

48 B. Greene, M. Hosea, R. McPherson, M. Henzl, M.D. Alexander, D.W. Darnall, Environ. Sci. Technol., 1986, 20, 677-632. 
49 A. Ahmad, P. Mukherjee, D. Mandal, S. Senapati, M.I. Khan, R. Kumar, M. Sastry, J. Am. Chem. Soc., 2002. 124, 12108-12109.

50 S.A. Kumar, M.K. Abyaneh, S.W. Gosavi, S.K. Kulkarni, A. Ahmad, M.I. Khan, Appl. Biochem., 2007, 47, 191-195.

51 J.P. Xie, J.Y. Lee, D.I.C. Wang, Y.P. Ting, Small, 2007, 3, 672-682.

\section{Tables}

Table 1 - Parameters of the filtrated bioreactor's effluent (BRI) before addition to the gold(III) solution

\begin{tabular}{ccccc}
\hline Parameters & pH & Eh $(\mathbf{m V})$ & $\begin{array}{c}\text { Sulphate } \\
\text { concentration } \\
\text { (mg/L) }\end{array}$ & $\begin{array}{c}\text { Sulphide } \\
\text { concentration } \\
(\mathbf{m g} / \mathbf{L})\end{array}$ \\
\hline $\begin{array}{c}\text { Bioreactor's } \\
\text { effluent (BRI) }\end{array}$ & 8.09 & -395 & 44 & 156 \\
\hline
\end{tabular}

Table 2 - Parameters of the filtrated effluents from BRI and BRII before the addition of the gold(III) solution

\begin{tabular}{ccccc}
\hline Parameters & pH & Eh $(\mathbf{m V})$ & $\begin{array}{c}\text { Sulphate } \\
\text { concentration } \\
\text { (mg/L) }\end{array}$ & $\begin{array}{c}\text { Sulphide } \\
\text { concentration } \\
\text { (mg/L) }\end{array}$ \\
\hline $\begin{array}{c}\text { Bioreactor's I } \\
\text { effluent }\end{array}$ & 6.44 & -329 & 26 & 398 \\
\hline $\begin{array}{c}\text { Bioreactor's II } \\
\text { effluent }\end{array}$ & 6.83 & -292 & 27 & 140 \\
\hline
\end{tabular}


Table 3 - Summarizing table:

Results of gold recovery and particles characterization in each experiment

\begin{tabular}{|c|c|c|c|c|c|c|}
\hline System & Experiment & $\begin{array}{c}\text { Gold } \\
\text { removal } \\
(\%)\end{array}$ & XRD & TEM & EDS & $\begin{array}{l}\text { Particles } \\
\text { Size }\end{array}$ \\
\hline \multirow[t]{2}{*}{ Batch } & A1 & 100 & $\begin{array}{c}\text { Cubic } \\
\text { Gold } \\
\text { Sulphide } \\
\left(\mathrm{Au}_{2} \mathrm{~S}\right)\end{array}$ & $\begin{array}{c}\text { Spherical } \\
\text { morphology, } \\
\text { Agglomerated }\end{array}$ & Au and $S$ & $6-14 \mathrm{~nm}$ \\
\hline & A2 & 62 & $\begin{array}{c}\text { Cubic } \\
\text { Gold } \\
(\mathrm{Au}(0))\end{array}$ & $\begin{array}{c}\text { Spherical } \\
\text { morphology, } \\
\text { Agglomerated }\end{array}$ & $\mathrm{Au}$ & $<8 n m$ \\
\hline \multirow[t]{2}{*}{ Continuous } & B1 & 76 & $\begin{array}{l}\text { Cubic } \\
\text { Gold } \\
(\mathrm{Au}(0))\end{array}$ & $\begin{array}{c}\text { Spherical and } \\
\text { hexagonal } \\
\text { morphology, } \\
\text { Agglomerated }\end{array}$ & $\mathrm{Au}$ & $\begin{array}{c}\text { 6-10 nm } \\
\text { (spherical); } \\
30-80 \mathrm{~nm} \\
\text { (hexagonal) }\end{array}$ \\
\hline & B2 & 100 & $\begin{array}{c}\text { Cubic } \\
\text { Gold } \\
(\mathrm{Au}(0))\end{array}$ & $\begin{array}{c}\text { Spherical } \\
\text { morphology, } \\
\text { Agglomerated }\end{array}$ & $\mathrm{Au}$ & $8-15 \mathrm{~nm}$ \\
\hline
\end{tabular}




\section{A- Batch Experiments}

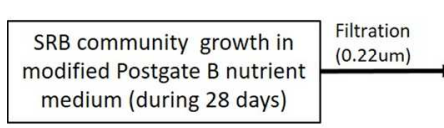

AMD from S. Domingos Mine (polysulphide Mine)
Treatment in BRI

$\longrightarrow$

\author{
A1 - Filtrated supernadant \\ from SRB growth and activity \\ in nutrient medium
} A2 - Filtrated bioreactor's
effluent

(with biogenic sulphide) from BRI

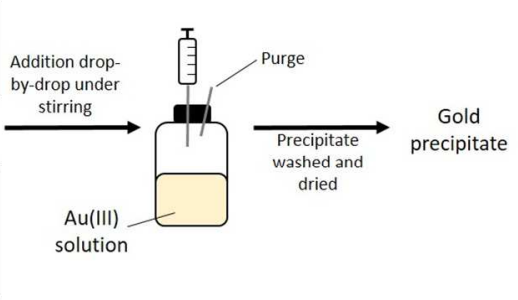

Scheme of the batch experiments aiming gold removal/recovery from aqueous medium. Sequential steps for gold recovery, in a batch system, using filtrated supernatant from SRB growth in modified Postgate B nutrient medium (Experiment A1) or using bioreactor's effluent from a SRB bioremediation process for S. Domingos mine AMD treatment, from Bioreactor I (BRI) (Experiment A2).

2.1. Batch Experiments for gol $245 \times 78 \mathrm{~mm}(150 \times 150 \mathrm{DPI})$ 


\section{B- Continuous Experiments}

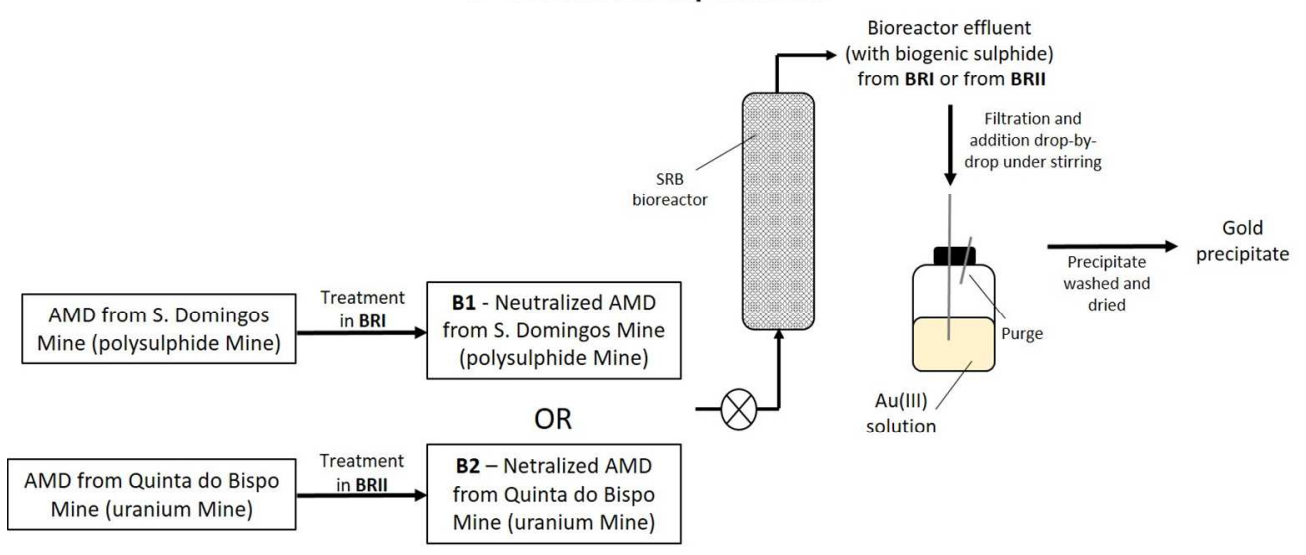

Scheme of the continuous experiments aiming gold removal/recovery from aqueous medium. Sequential steps for gold recovery, in a continuous system, using two different bioreactor's effluents, one from the treatment of an AMD originated from a polysulphide mine (Experiment B1) and the other one from the treatment of an AMD coming from an uranium mine (Experiment B2).

Figure 2 shows a scheme of the

$256 \times 117 \mathrm{~mm}(150 \times 150 \mathrm{DPI})$ 


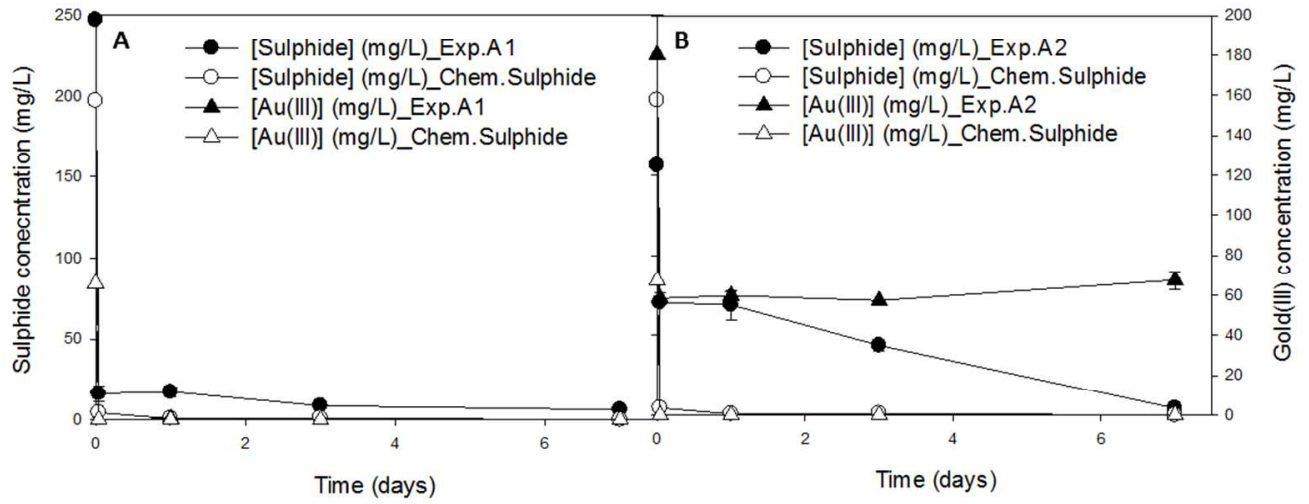

Evolution of sulphide and gold(III) concentration in Experiment $A 1$ ( $)$ ) and Experiment $A 2$ (B), throughout the time. In $A$ and $B$ graphs, the white symbols represent the chemical control with chemical sulphide (white circle) and gold(III) concentrations (white triangle). The black symbols represent the biogenic sulphide concentration (black circle) and the gold(III) concentration (black triangle). Data are the average of four replicates in Experiment $\mathrm{A} 1$ and $\mathrm{A} 2$, while in assays with the chemical sulphide the data are the average of duplicates. The error bars indicate the standard deviations of the average values (in some cases error bars are smaller than symbols, therefore not visible).

The results are shown in figur $304 \times 136 \mathrm{~mm}(96 \times 96$ DPI) 


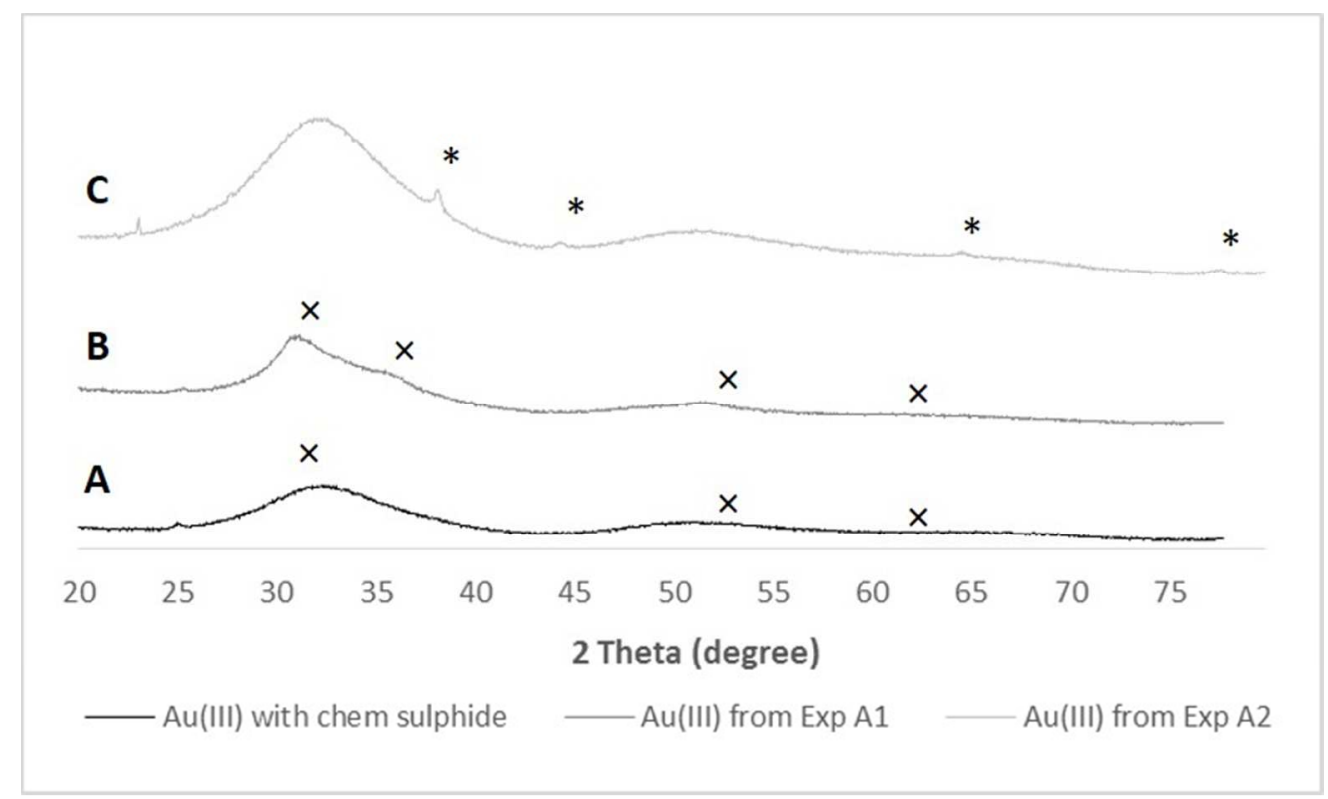

X-Ray powder diffraction patterns for precipitates generated in batch assays: (A) Precipitate obtained using a "chemical" solution of sulphide; (B) precipitate obtained in experiment $A 1 ;(C)$ precipitate obtained in experiment $\mathrm{A} 2$.

The XRD diffractograms of the $145 \times 87 \mathrm{~mm}(150 \times 150 \mathrm{DPI})$ 


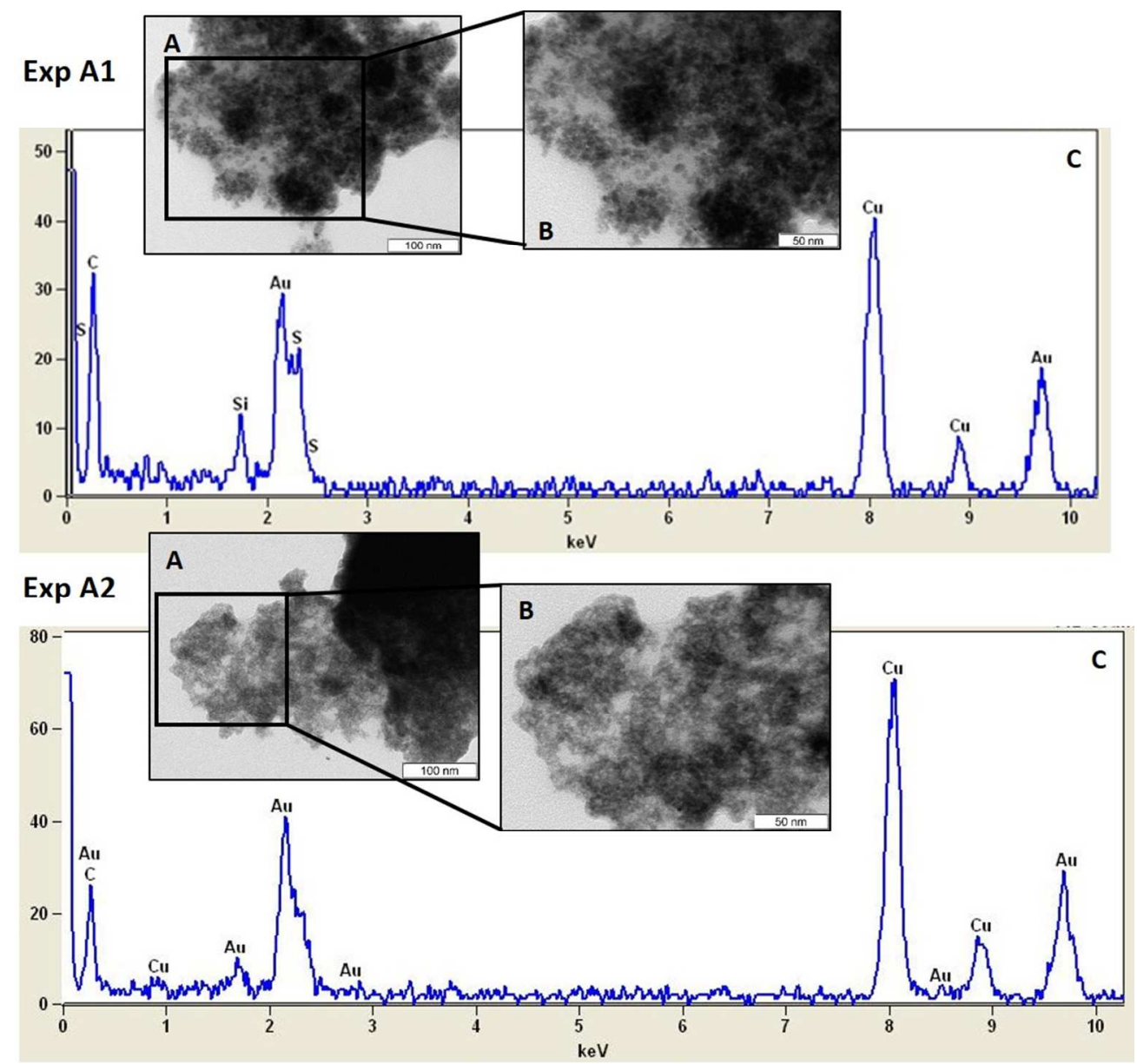

TEM images and corresponding EDS spectrum of the precipitates obtained in Experiments $A 1$ and $A 2$. figure $5-\mathrm{A} 1 \mathrm{~A}$ and $\mathrm{B}$, confirms $192 \times 178 \mathrm{~mm}(150 \times 150 \mathrm{DPI})$ 


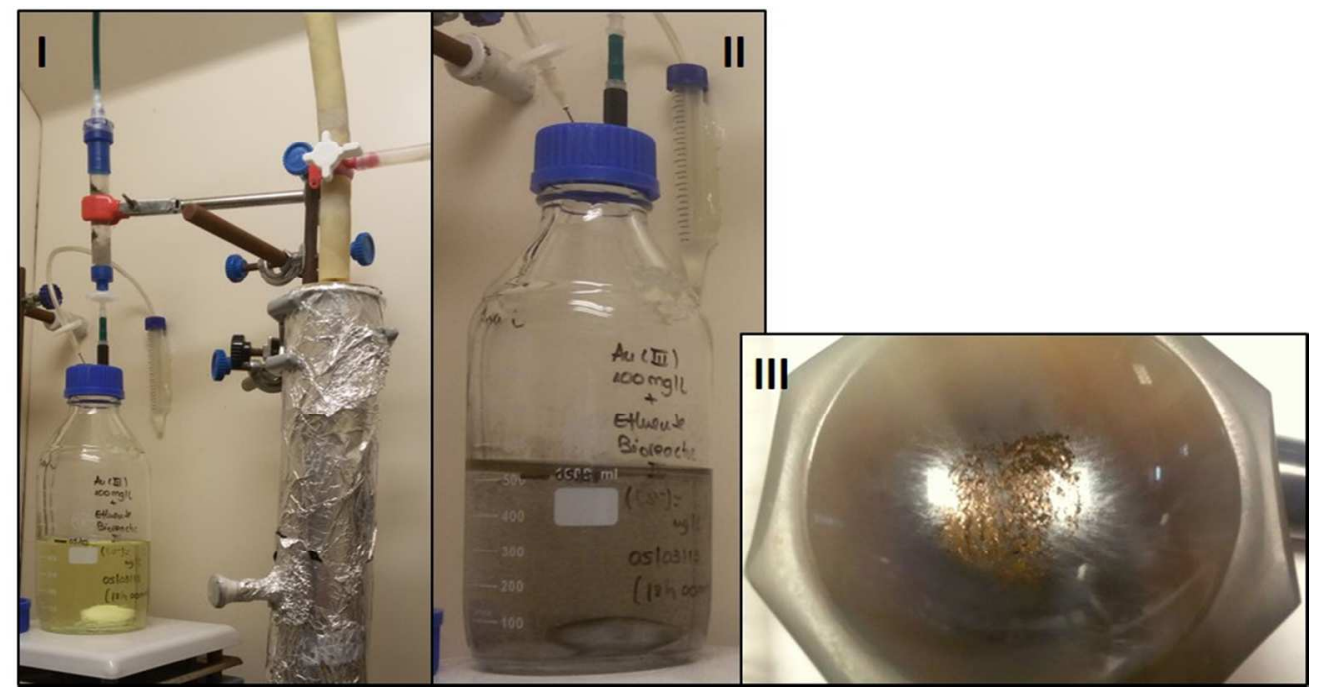

Pictures of the: I - Au(III) recovery coupled to the bioremediation system - flask containing the Au(III) solution before addition of the bioreactor's effluent; II - mixture of Au(III) solution with the bioreactor's effluent during the addition of the bioreactor's effluents; III - obtained gold precipitate.

AMD bioremediation process, ar $172 \times 90 \mathrm{~mm}(150 \times 150 \mathrm{DPI})$ 


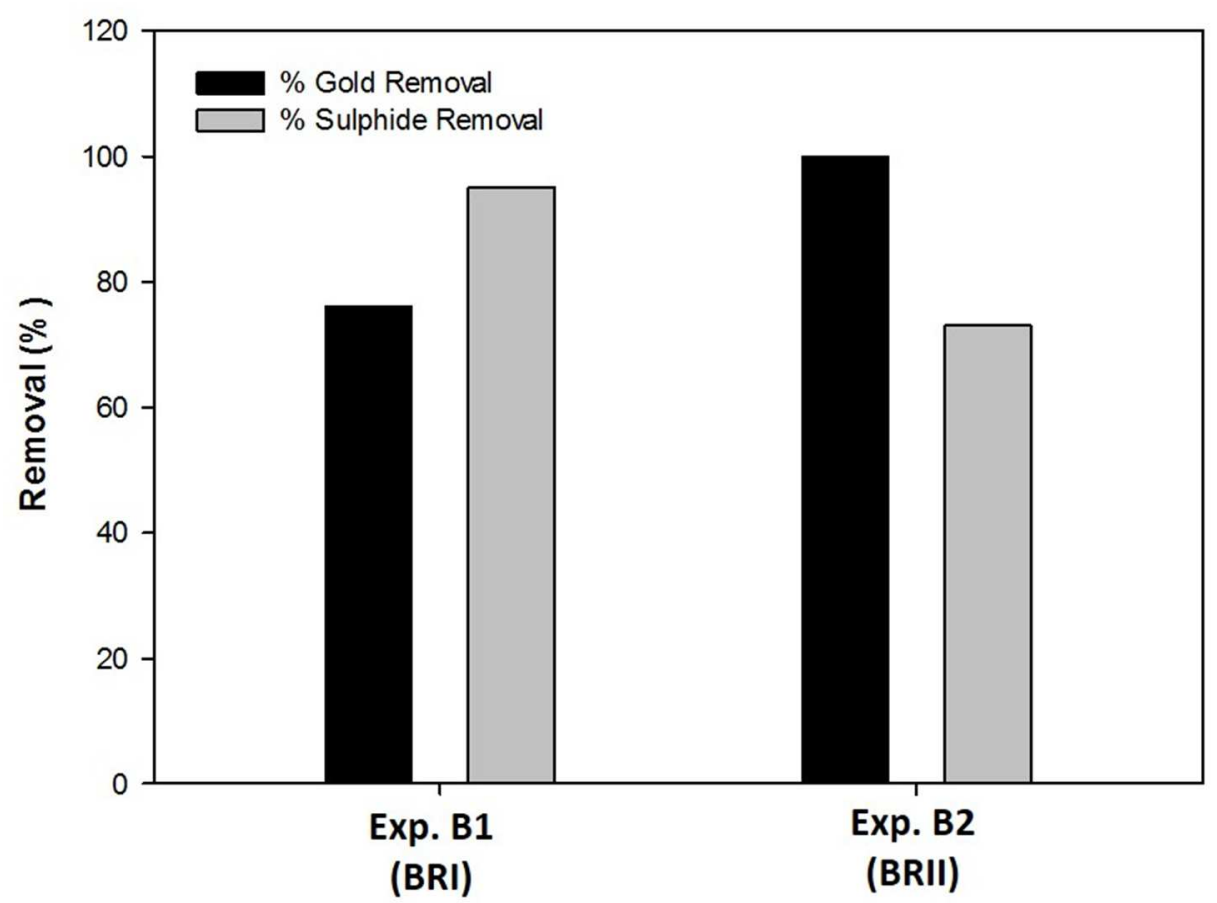

Percentage of gold (III) (in grey) and sulphide (in black) removal for both continuous system (Experiments $\mathrm{B} 1$ and $\mathrm{B} 2$ ).

Figure 7 contains the percenta $155 \times 120 \mathrm{~mm}(150 \times 150 \mathrm{DPI})$ 


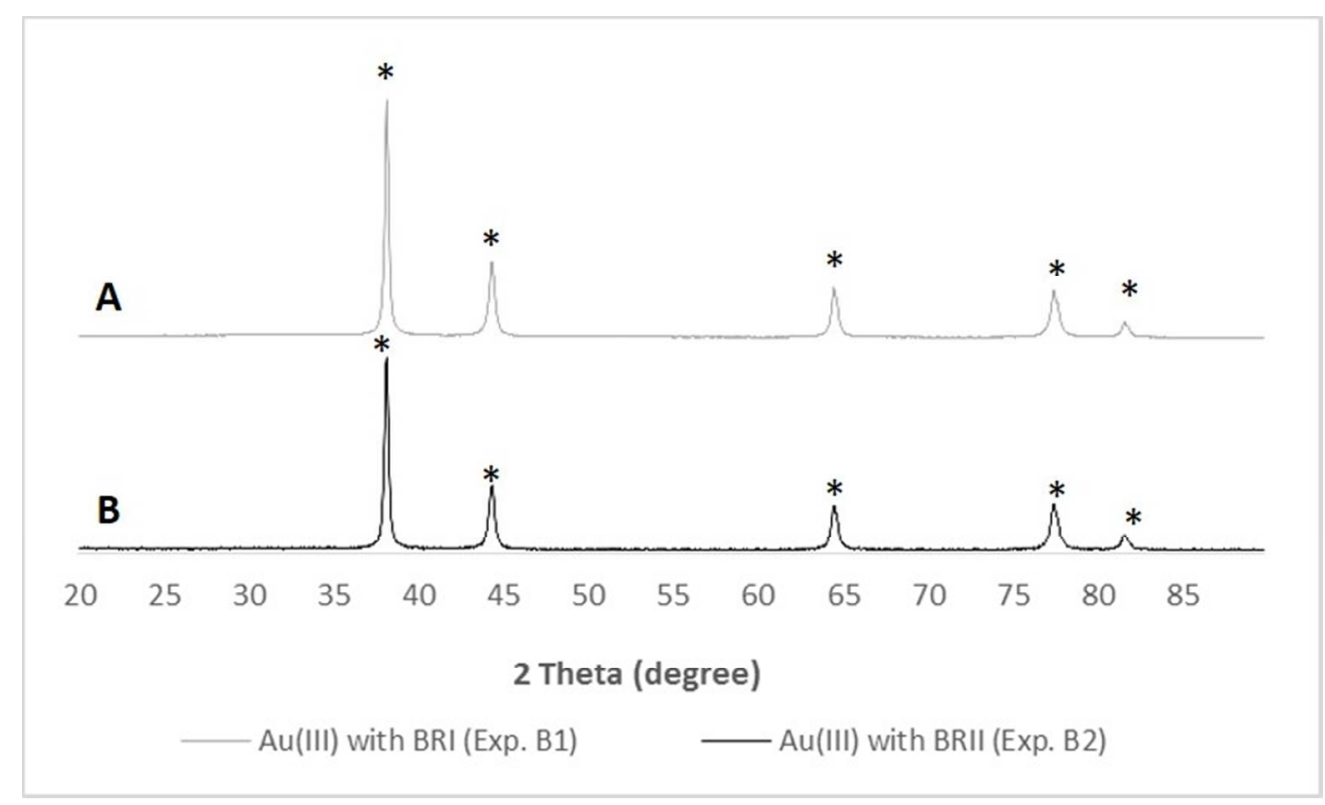

$X$-Ray powder diffraction patterns of the precipitates generated in the continuous assays using the effluent from the BRI - Experiment B1 (A) and from BRII -Experiment B2 (B).

The XRD analysis of the precip

$145 \times 87 \mathrm{~mm}(150 \times 150 \mathrm{DPI})$ 

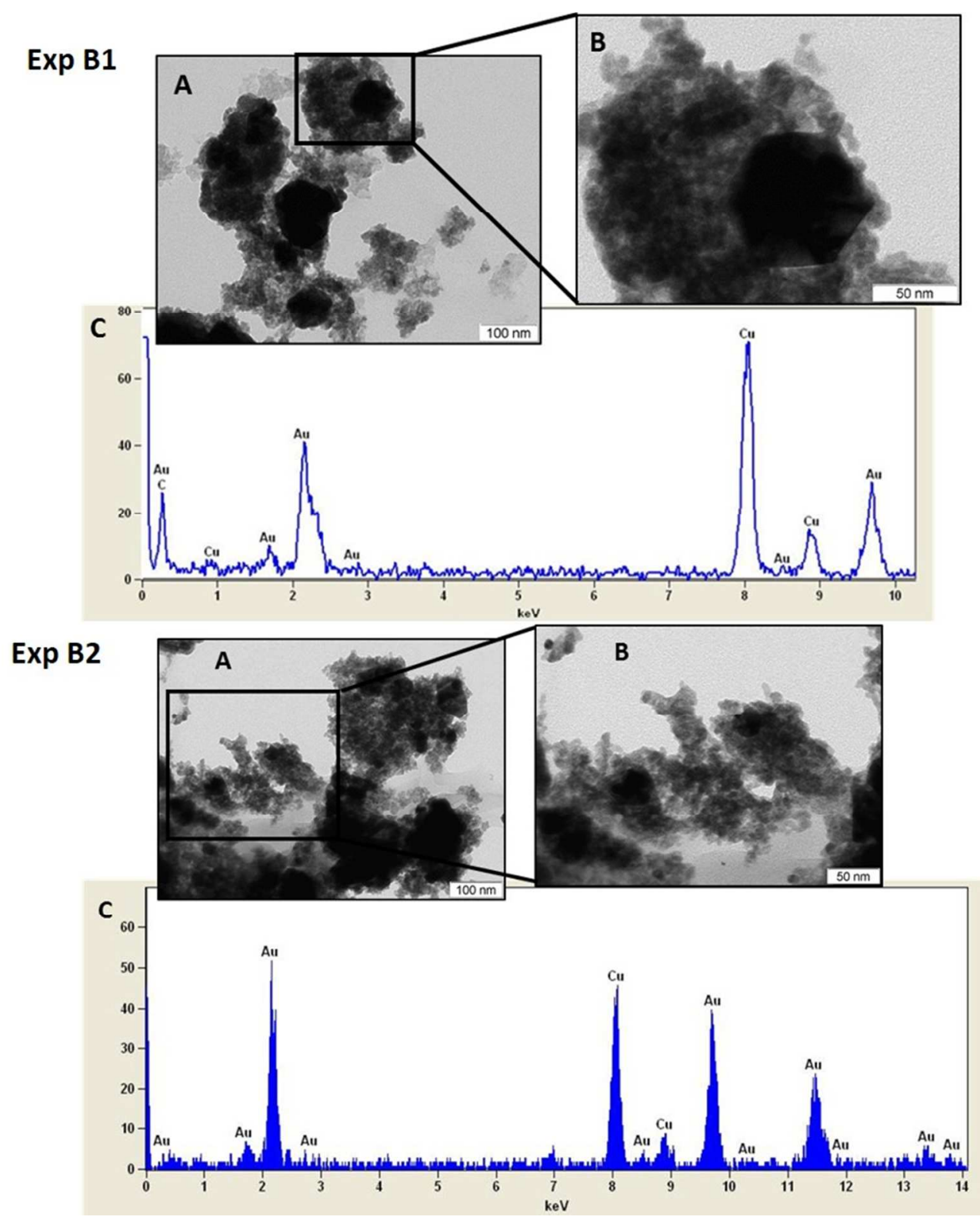

TEM images and corresponding EDS spectrum of the nanosized particles of $\mathrm{Au}(0)$ obtained in experiments $\mathrm{B} 1$ and $\mathrm{B} 2$.

TEM results of the precipitate $150 \times 181 \mathrm{~mm}(150 \times 150 \mathrm{DPI})$ 